\title{
Low-carbohydrate diets differing in carbohydrate restriction improve cardiometabolic and anthropometric markers in healthy adults: A randomised clinical trial
}

\author{
Cliff J d C Harvey ${ }^{\text {Corresp.., }}{ }^{1}$ ， Grant M Schofield ${ }^{1}{ }^{\text {, }}$ Caryn Zinn ${ }^{1}$, Simon J Thornley ${ }^{1}$, Catherine Crofts ${ }^{1}$, Fabrice L \\ R Merien ${ }^{2}$ \\ 1 Human Potential Centre, Auckland University of Technology, Auckland, New Zealand \\ 2 AUT-Roche Diagnostics Laboratory, School of Science, Auckland University of Technology, Auckland, New Zealand \\ Corresponding Author: Cliff J d C Harvey \\ Email address: cliff@hpn.ac.nz
}

Background. Low-carbohydrate, high-fat (LCHF) diets are useful for treating a range of health conditions, but there is little research evaluating the degree of carbohydrate restriction on outcome measures. This study compares anthropometric and cardiometabolic outcomes between differing carbohydrate-restricted diets.

Objective. Our hypothesis was that moderate carbohydrate restriction is easier to maintain and more effective for improving cardiometabolic health markers than greater restriction.

Design. Seventy-seven healthy participants were randomised to a very low carbohydrate ketogenic diet (VLCKD), low-carbohydrate diet (LCD), or moderate-low carbohydrate diet (MCD), containing 5\%, 15\% and $25 \%$ total energy from carbohydrate respectively, for 12 -weeks. Anthropometric and metabolic health measures were taken at baseline and at 12 weeks. Using ANOVA, both within and between-group outcomes were analysed.

Results. Of 77 participants, 39 (51\%) completed the study. In these completers overall, significant reductions in weight and body mass index occurred ([mean change] $3.7 \mathrm{~kg} / \mathrm{m}^{2} ; 95 \%$ confidence limits $[C L]: 3.8,1.8)$, along with increases in high-density lipoprotein cholesterol, low-density lipoprotein cholesterol, $(0.49 \mathrm{mmol} / \mathrm{L} ; 95 \% \mathrm{CL} ; 0.06,0.92 ; p=0.03)$, and total cholesterol concentrations $(0.11$ $\mathrm{mmol} / \mathrm{L} ; 95 \% \mathrm{CL} ; 0.00,0.23 ; p=0.05)$. Triglyceride (TG) levels were reduced by $0.12 \mathrm{mmol} / \mathrm{L}(95 \% \mathrm{CL}$; $0.20,0.02 ; p=0.02$ ). No significant changes occurred between groups. The largest improvements in HDL-C and TG and anthropometric changes occurred for the VLCKD group.

Conclusions. LCHF diets have a positive effect on markers of health. Adherence to the allocation of carbohydrate was more easily achieved in MCD, and LCD groups compared to VLCKD and there were comparable improvements in weight loss and waist circumference and greater improvements in HDL-C and TG with greater carbohydrate restriction. 
Low-carbohydrate diets differing in carbohydrate restriction improve cardiometabolic and anthropometric markers in healthy adults: A randomised clinical trial

Cliff J. d C. Harvey, ${ }^{1}$ Grant M. Schofield, ${ }^{1}$ Caryn Zinn, ${ }^{1}$ Simon J. Thornley, ${ }^{1}$ Catherine Crofts, ${ }^{1}$ Fabrice L.R. Merien²

${ }^{1}$ Human Potential Centre, AUT University, Auckland, New Zealand

${ }^{2}$ AUT-Roche Diagnostics Laboratory, School of Science, AUT University, Auckland, New

Zealand

Corresponding author:

Cliff Harvey

7a Ascension Place, Rosedale, Auckland 0632, New Zealand.

Email address: cliff@hpn.ac.nz 


\section{Abstract}

2 Background. Low-carbohydrate, high-fat (LCHF) diets are useful for treating a range of health

3 conditions, but there is little research evaluating the degree of carbohydrate restriction on

4 outcome measures. This study compares anthropometric and cardiometabolic outcomes between

5 differing carbohydrate-restricted diets.

6 Objective. Our hypothesis was that moderate carbohydrate restriction is easier to maintain and

7 more effective for improving cardiometabolic health markers than greater restriction.

8 Design. Seventy-seven healthy participants were randomised to a very low carbohydrate

9 ketogenic diet (VLCKD), low-carbohydrate diet (LCD), or moderate-low carbohydrate diet

10 (MCD), containing 5\%, 15\% and 25\% total energy from carbohydrate respectively, for 12 -

11 weeks. Anthropometric and metabolic health measures were taken at baseline and at 12 weeks.

12 Using ANOVA, both within and between-group outcomes were analysed.

13 Results. Of 77 participants, 39 (51\%) completed the study. In these completers overall,

14 significant reductions in weight and body mass index occurred ([mean change] $3.7 \mathrm{~kg} / \mathrm{m}^{2} ; 95 \%$

15 confidence limits [CL]: 3.8, 1.8), along with increases in high-density lipoprotein cholesterol,

16 low-density lipoprotein cholesterol, $(0.49 \mathrm{mmol} / \mathrm{L} ; 95 \% \mathrm{CL} ; 0.06,0.92 ; p=0.03)$, and total

17 cholesterol concentrations $(0.11 \mathrm{mmol} / \mathrm{L} ; 95 \% \mathrm{CL} ; 0.00,0.23 ; p=0.05)$. Triglyceride $(\mathrm{TG})$

18 levels were reduced by $0.12 \mathrm{mmol} / \mathrm{L}(95 \% \mathrm{CL} ;-0.20,0.02 ; p=0.02)$. No significant changes

19 occurred between groups. The largest improvements in HDL-c and TG and anthropometric

20 changes occurred for the VLCKD group.

21 Conclusions. LCHF diets have a positive effect on markers of health. Adherence to the

22 allocation of carbohydrate was more easily achieved in MCD, and LCD groups compared to 
23 VLCKD and there were comparable improvements in weight loss and waist circumference and

24 greater improvements in HDL-c and TG with greater carbohydrate restriction. 


\section{Introduction}

26 Low-carbohydrate, high-fat (LCHF) and very low-carbohydrate ketogenic diets (VLCKD) are

27 increasingly used for the management of a range of health conditions, including neurological

28 disorders, obesity, diabetes, metabolic syndrome, and various cancers. (Castro et al. 2015;

29 Henderson et al. 2006; Keene 2006; Kulak \& Polotsky 2013; Lefevre \& Aronson 2000; Levy et

30 al. 2012; Maalouf et al. 2009; Neal et al. 2008; Paoli et al. 2013; Sumithran \& Proietto 2008;

31 Varshneya et al. 2015) They are also used widely in the general population for weight-loss and

32 maintenance, (Bueno et al. 2013) with improved satiety and control of hunger frequently

33 reported by those who adhere to these diets. (Johnstone et al. 2008; McClernon et al. 2007; Paoli

34 et al. 2015) Despite the potential offered by LCHF and low-carbohydrate, high-protein (LCHP)

35 diets, there is little evidence for the superiority of greater carbohydrate restriction compared to

36 moderate. Systematic reviews show that despite greater weight- and fat-loss initially, over longer

37 timeframes, when energy intake is restricted, there is little difference in outcomes for weight-

38 loss, total and low density liproprotein cholesterol (LDL-c) concentrations between diets that are

39 higher or lower in carbohydrate. (Hernández Alcantara et al. 2015; Huntriss et al. 2017; Naude et

40 al. 2014; Snorgaard et al. 2017; van Wyk et al. 2016) However, there are greater reductions in

41 fasted glucose concentrations, (Snorgaard et al. 2017) and greater improvements in high density

42 lipoprotein cholesterol (HDL-c) and glycated haemoglobin (HbA1c) with greater degrees of

43 carbohydrate restriction. (Huntriss et al. 2017) Controversy exists about the nature of low-

44 carbohydrate diets (LCD) and VLCKDs, (Wood \& Fernandez 2009) and definitions for LCDs

45 range from 20-200 g of carbohydrate per day, (Last \& Wilson 2006; Westman et al. 2007) or up

46 to $40-45 \%$ of daily energy from carbohydrate. (2012; Wheeler et al. 2012) Definitions for

47 VLCKDs are similarly vague. The accepted definition for nutritional ketosis (NK) in the clinical

48 nutrition field has become the achievement of $\geq 0.5 \mathrm{mmol} / \mathrm{L} \beta$ - hydroxybutyrate $(\mathrm{BOHB})$, as the 
49 majority of people following a VLCKD achieve this level of blood ketones (Gibson et al. 2015),

50 and this threshold has been used by several studies as an indicator of entry into NK. (Guerci et al.

51 2003; Harvey et al. 2018) Ketonaemia consistent with NK typically results from diets containing

52 a 3:1 to 4:1 ratio of lipids to non-lipid macronutrients, or at least $75 \%$ of calories coming from

53 lipids, very low carbohydrates (often less than $50 \mathrm{~g}$ ) and low-to-moderate amounts of protein,

54 (Livingston et al. 1977; Livingstone 1972) or diets containing 60\%-75\% of calories from lipids

55 that include a high proportion of medium chain triglycerides (MCTs). (Huttenlocher et al. 1971;

56 Huttenlocher 1976) Studies report that adherence is difficult with extreme carbohydrate

57 restriction, i.e. $<50$ g of carbohydrate per day, (Huntriss et al. 2017) but insulin-resistant (IR)

58 people may be less likely to adhere to a low-fat, high-carbohydrate diet, compared to those who

59 are more insulin-sensitive (IS). Adherence and weight-loss are similar between both IR and IS

60 participants allocated to a less restrictive low-carbohydrate diet. (McClain et al. 2013)

61 Few studies directly compare very low-carbohydrate diets with less extreme carbohydrate-

62 restricted diets. Johnstone and colleagues compared the effects of a non-ketogenic low-

63 carbohydrate diet (fat $30 \%$ of total energy (TE); carbohydrate $40 \%$ of TE) to a ketogenic, low-

64 carbohydrate diet (fat 60\% TE; carbohydrate 5\% TE) in twenty adults over six weeks, finding

65 that the diets were equally effective in reducing body weight and insulin resistance. (Johnston et

66 al. 2006)

67 Our hypothesis was that moderate carbohydrate restriction may be easier to maintain, and thus

68 more effective than greater degrees of carbohydrate restriction. The aim of the present study

69 therefore, is to compare anthropometric and cardiometabolic outcomes between a VLCKD, LCD

70 and moderate-low carbohydrate diet (MCD), containing 5\%, 15\% and 25\% TE from

71 carbohydrate respectively, in healthy adults. 


\section{Materials and Methods}

73 Population

74 Seventy-seven participants, 25 males, 52 females (mean age: 39 years, range: 25 to 49; mean

75 BMI $27 \mathrm{~kg} / \mathrm{m}^{2}$, range: $\left.20-39\right)$ were recruited between the $7^{\text {th }}$ and $19^{\text {th }}$ of August 2017 and gave

76 written, informed consent to participate in this 12-week, randomised, clinical intervention study.

77 The study took place between $11^{\text {th }}$ September and $10^{\text {th }}$ December 2017 . Collection of data and

78 analysis was performed at AUT's Human Potential Centre, Auckland, New Zealand.

\section{Inclusion and exclusion criteria}

80 Participants were required to be healthy and between the ages of 25 and 49 years. Exclusion

81 criteria were; underweight $\left(<18.5 \mathrm{BMI} \mathrm{kg} / \mathrm{m}^{2}\right)$, diagnosed with diabetes, diagnosed with any

82 serious medical condition, having previously following a ketogenic diet, or being a current or

83 former client of any of the researchers in clinical practice.

\section{Ethical approval}

85 The trial was registered by the Australia New Zealand Clinical Trial Registry.

86 (ACTRN12617000421336p). Ethics approval for this study was granted by the Southern

87 Committee of the Health and Disability Ethics Committee of New Zealand. 17/STH/60

Dietary interventions and allocation

89 Participants completed baseline testing of blood and basic anthropometric measures and a lead-in

90 dietary recording week to identify habitual calorie intake. Participants were randomised by the

91 study statistician to one of three low-carbohydrate diet plans which advised intakes of either 5\%,

$9215 \%$, or $25 \%$ of TE from carbohydrate. The randomisation was stratified by gender, using a pre- 
93 prepared sequence, with investigators blinded to treatment allocation at baseline and follow-up.

94 Participants were assigned to the next treatment group according to their order of recruitment.

95 The primary researcher responsible for initial statistical analysis was blinded to the treatment

96 group allocation until this analysis had been completed.

97 Diet plans, which included macronutrient and calorie allocation and a sample menu plan, were

98 individualised to the participant, with energy intake determined by the mean reported energy

99 consumed per day in the lead-in dietary recording week. Advice was given to limit protein intake

100 to $1.4 \mathrm{~g} / \mathrm{kg} / \mathrm{d}$ (weight at baseline testing), consistent with International Society of Sports

101 Nutrition guidelines for optimal protein intake for performance. (Campbell et al. 2007) This was

102 chosen as an appropriate protein intake that was not likely to unduly influence the study results,

103 because the study participants were healthy people, who may also be engaged in physical activity

104 and sports. Participants were advised to adhere as strictly as possible to the energy and

105 macronutrient prescription for the first three weeks of the intervention. For the final nine weeks

106 of the intervention, they were advised to eat ad libitum but to adhere as closely as possible to the

107 carbohydrate energy limit for their treatment group as a percentage of their total energy intake.

108 Usual exercise patterns were continued. Dietary intake was recorded by participants in a mobile

109 application (Fat Secret) with the researchers able to obtain real time entry on a partner mobile

110 application (Fat Secret Pro). Results were monitored for safety and compliance by the primary

111 researcher and research assistants tasked with data-monitoring. Compliance to the dietary

112 allocation was monitored daily by a data monitoring team. Where non-compliance to the dietary

113 allocation, especially for carbohydrate, was noticed, the participant was notified and offered

114 support and advice.

115 Figure 1 profiles the instructions for the dietary allocations over the 13-week study course. 
116 [Figure 1.]

117 Figure 1. Flow-chart showing instructions for the dietary allocations

118 Participants were instructed to contact either the clinical nutritionist or the registered dietitian in

119 the research team for any assistance during the study duration.

120 Anthropometry

121 The following measures were taken: height, weight, waist circumference at the narrowest point

122 between the lowest rib and the iliac crest, and hip circumference at the widest point of the hips

123 and buttocks. These measures were then used to derive body mass index (BMI), waist-hip ratio,

124 and the waist-height ratio at baseline and during follow-up.

\section{Blood measures}

126 Following an overnight fast, blood samples were obtained from participants, before the first

127 meal, via venipuncture by a certified phlebotomist from an antecubital vein and collected into

128 PST Vacutainer tubes using lithium-heparin as the anticoagulant (Becton Dickinson). Within 15

129 minutes of collection, tubes were centrifuged at 1500 revolutions per minute for $10 \min$ at $+4^{\circ} \mathrm{C}$,

130 and plasma samples were transferred into clean polypropylene tubes and frozen at $-80^{\circ} \mathrm{C}$ until

131 analyses were conducted using specific diagnostics assays on a Roche Modular analyser (P800

132 and E170). Blood samples were analysed for total cholesterol (Total-c), LDL-c, HDL-c,

133 triglycerides (TG), C-reactive protein (CRP), gamma-glutamyl transferase (GGT), alanine

134 aminotransferase (ALT), aspartate aminotransferase (AST), alkaline phosphatase (ALP), glucose

135 and uric acid on the P800 module. Insulin, and C-peptide concentrations were measured on the

136 E170 module. All analytical biomarkers were measured at baseline and immediately following

137 the 12-week intervention. The total duration of the assay for each analyte was less than 20 min 
138 based on the electrochemiluminescence principle (ruthenium-conjugated monoclonal antibodies)

139 for the E170 module and specific enzyme assay methods for the P800 module. Quantitative

140 results were determined via instrument-specific full point calibration curves and validated with

141 specific controls. Additional information for analytes, lower limits of measurement, measuring

142 range, and test principle can be found in appendix 1.

\section{Statistical analyses}

144 Effects of the dietary interventions on outcomes were determined for each participant by

145 calculating the change in the various measures from baseline. The significance of these within-

146 group changes from baseline was determined by a paired t-test. All between-group variations

147 were compared using ANOVA. A 5\% two-sided alpha level was used to determine significance.

148 Further comparisons were made by undertaking multiple linear regression with adjustment made

149 for variables recorded at baseline. A sensitivity analysis of the results was carried out using 150 stabilised inverse-probability of completing weights for the BMI change outcome to check

151 whether these results were likely to have been different had the whole group returned for 152 followed-up.

\section{Results}

154 A total of 283 people were assessed for eligibility with 206 excluded and 77 included for 155 randomisation to the trial groups (Figure 2). Ten participants withdrew after they were 156 randomised. Two failed to comply with guidelines to submit baseline data and withdrew from 157 the study (one male, one female), and three females withdrew due to changes in personal 158 circumstances, including two who became pregnant. A further five withdrew due to challenges 159 arising from following the diets. The reasons for withdrawals were as follows: two female 
160 participants found the dietary allocation of carbohydrate too difficult to sustain (one each in the

$1615 \%$ and $15 \%$ allocation groups); one did not want to continue tracking with the food app; one felt

162 that she could not maintain her sports performance on $15 \%$ total energy from carbohydrate; and

163 one female in the 5\% allocation group reported amenorrhea and reductions in strength and

164 power, despite improved mental clarity. A further 28 did not book for or failed to present for

165 post-intervention measurements. This left 39 participants with follow-up results available for

166 analysis.

167 There were no significant differences in baseline characteristics between completers and 168 non-completers and no meaningful difference in the number of non-completers by group with $16950 \%, 50 \%$, and $48 \%$ of participants not completing post-intervention measures in the MCD,

170 LCD, and VLCKD groups respectively. Mean baseline levels of TG were, however, 36\% higher

171 at baseline in those lost to follow-up compared to those who were not, even though the

172 difference between the two distributions was not significant $(p=0.08)$. There was also no

173 significant variation for age, gender, or ethnicity between the groups, in the participants

174 analysed. At baseline, blood measures were all within reference ranges except for Total-c which

175 had an overall mean of $5.31 \mathrm{mmol} / \mathrm{L}(\mathrm{SD}=1.29)$ for completers, and a significant between-

176 group difference $(p=0.005)$.

177 Baseline characteristics of those included for analysis are presented in Table 1, by randomised

178 treatment group.

179 [Table 1. Baseline characteristics of study participants]

180 [Figure 2.]

181 Figure 2. Flow-chart showing participant recruitment, randomisation, allocation and lost-to182 follow-up 
184 Mean weight and BMI at baseline differed between groups ( $p=0.046$ and 0.050 respectively).

185 The LCD group had the highest starting BMI at baseline of $29.1 \mathrm{~kg} / \mathrm{m}^{2}(\mathrm{SD}=4.9)$, followed by

$186 \mathrm{MCD}\left(\mathrm{BMI}=26.4 \mathrm{~kg} / \mathrm{m}^{2}, \mathrm{SD}=3.2\right)$. The lowest starting BMI was in the VLCKD group with a

187 mean BMI of $25.5 \mathrm{~kg} / \mathrm{m}^{2}(\mathrm{SD}=2.8)$. Overall, there was a significant reduction in weight across

188 all groups $(p<0.001)$. Mean weight loss increased with the magnitude of carbohydrate

189 restriction, with $4.12 \mathrm{~kg}(\mathrm{SD}=2.54), 3.93 \mathrm{~kg}(\mathrm{SD}=3.71)$, and $2.97 \mathrm{~kg}(\mathrm{SD}=3.25)$ lost by the

190 VLCKD, LCD, and MCD groups respectively. However, the differences in weight loss between

191 these groups were not statistically significant $(p=0.626)$. Similarly, a highly significant change

192 in BMI of $-1.22 \mathrm{~kg} / \mathrm{m}^{2}(\mathrm{SD}=1.03, p<0.001)$ was recorded overall. While the reduction in BMI

193 was greater per magnitude of carbohydrate restriction, this difference was not significant $(p=$

194 0.686).

195 All dietary interventions led to reductions in both waist and hip girth. There was an overall 196 reduction in waist measurement of $2.85 \mathrm{~cm}(\mathrm{SD}=2.99)$ and hip girth reduced by $3.43 \mathrm{~cm}(\mathrm{SD}=$ $1974.67, p<0.001$ for both measures). The reduction in waist measurement girth did not differ 198 significantly by group $(p=0.99)$ but the change in hip girth approached the threshold for 199 significance $(p=0.06)$. There was a significant change overall to the waist-height ratio $(-0.02, p$ $200<0.001)$ but no significant difference between groups and no significant overall change in the 201 waist-hip ratio. All changes in measures, both overall and by group, with $95 \%$ confidence 202 intervals are reported in Table 2.

\section{Blood measures}


204 This paper focuses on the key cardiometabolic outcome measures of Total-c, LDL-c, HDL-c, 205 TG, CRP, glucose, and insulin. Liver enzymes and uric acid were included in the initial analysis 206 as they are emerging markers of interest for metabolic syndrome and insulin resistance. (Babio et 207 al. 2015; Ballestri et al. 2016) One participant had GGT levels above the reference range upper 208 limit of $60 \mathrm{U} / \mathrm{L}$. This was reduced from baseline to completion; $143 \mathrm{U} / \mathrm{L}$ to $106 \mathrm{U} / \mathrm{L}$. Another 209 participant had baseline levels of ALT of $79 \mathrm{U} / \mathrm{L}$ which normalised to $30 \mathrm{U} / \mathrm{L}$ at completion 210 (reference range upper limit, $45 \mathrm{U} / \mathrm{L}$ ). Overall, there was no meaningful change in liver enzymes 211 or uric acid and the differences between groups were not significant.

212 The most meaningful changes observed were for CRP and insulin. CRP was reduced in the MCD 213 and $\mathrm{LCD}$ treatment groups overall by $-3.90 \mathrm{mg} / \mathrm{L}(\mathrm{SD}=12.60)$, and $-3.04 \mathrm{mg} / \mathrm{L}(\mathrm{SD}=3.90)$, 214 respectively. There was a marginal increase in CRP in the VLCKD group of $0.14 \mathrm{mg} / \mathrm{L}$ ( $\mathrm{SD}=$ 215 1.10) which we would not consider to be meaningful. While the overall change from baseline 216 CRP approached the threshold for significance $(p=0.074)$, there was no difference between the 217 groups $(p=0.339)$. While at baseline, no significant difference for CRP was present between 218 groups $(p=0.346)$, there were several readings for CRP that were above the reference range 219 upper limit of $5 \mathrm{mg} / \mathrm{L}$. The highest reading of $46.9 \mathrm{mg} / \mathrm{L}$ was recorded in the MCD group and 220 there were also three readings $>5 \mathrm{mg} / \mathrm{L}$ in the $\mathrm{LCD}$ group, with the highest maximal reading of

$22113 \mathrm{mg} / \mathrm{L}$. Conversely, the maximal recorded value for CRP in the VLCKD group at baseline was $2222.6 \mathrm{mg} / \mathrm{L}$. On follow-up, all results were $<5 \mathrm{mg} / \mathrm{L}$.

223 Insulin concentration was reduced overall by $13.6 \mathrm{pmol} / \mathrm{L}(\mathrm{SD}=24.8, p<0.001)$. The greatest

224 change occurred in the LCD group, followed by the VLCKD group, with the smallest change in 225 the MLC group. The difference between groups, however, was not statistically significant ( $p=$ $2260.185)$. 
227 Statistically significant changes, albeit of a relatively small magnitude, occurred for Total-c,

228 LDL-c and HDL-c, which were all increased at completion vs baseline, and for TG which were

229 reduced, with no significant variation between groups. No meaningful change from baseline was

230 observed for fasted glucose. There was however, a significant improvement in the TG-HDL ratio

231 of $-0.102(\mathrm{SD}=0.220, p=0.006)$. This improvement was increased with greater carbohydrate

232 restriction with changes of $-0.023(\mathrm{SD}=0.158),-0.118(\mathrm{SD}=0.291)$ and $-0.154(\mathrm{SD}=0.182)$,

233 for MCD, LCD, and VLCKD respectively ( $p=0.308)$.

234 Large proportional changes from baseline occurred for insulin, TG, Total-c, LDL-c and HDL-c.

235 Proportional increases from baseline for Total-c and LDL-c were greatest for LCD, followed by

236 VLCKD, and MCD. There was no relative change from baseline for both TG and HDL-c in the

237 MCD group. Improvements in HDL-c and TG occurred for the LCD group, with the greatest

238 proportional change in the VLCKD group. There were relatively minor proportional changes for

239 the remaining measures. (Figure 3.) All changes in reported measures, overall and by group, with

$24095 \%$ confidence intervals, are reported in Table 2.

241 [Figure 3.]

242 Figure 3. Percent change in outcome measures from baseline. MCD, moderately-low

243 carbohydrate diet; LCD, low-carbohydrate diet; VLCKD, very-low-carbohydrate ketogenic diet;

244 BMI, body mass index; LDL, low-density lipoprotein; HDL, high-density lipoprotein; TG,

245 triglyceride; CRP, c-reactive protein

\section{Adherence to diet}

247 The individual mean daily energy intake per group, by week, is shown in Figure 4. A marginal

248 increase in reported energy intake occurred during the first three weeks, during which time 
249 participants had been advised to maintain usual energy intake. After the first three weeks,

250 participants had been advised to eat ad libitum but preserve the carbohydrate allocation as a

251 percentage of total energy intake. In this phase, the pattern of increased energy over baseline was

252 maintained over most weeks but eventually declined. By week 12 there was an overall reduction

253 in mean energy compared to baseline of $66 \mathrm{Kcal}, 95 \mathrm{Kcal}$, and $192 \mathrm{Kcal}$ for MCD, LCD, and

254 VLCKD respectively. So, overall there was a greater magnitude of energy increase initially with 255 greater carbohydrate restriction, but over time this resulted in a greater reduction in total energy

256 consumed commensurate with the magnitude of carbohydrate restriction. These changes from

257 baseline were relatively small with the greatest magnitude of change from baseline, $12 \%, 10 \%$, 258 and $18 \%$ for MCD, LCD, and VLCKD respectively.

259 [Figure 4.]

260 Figure 4. Mean reported daily energy intake (Kcal) per week by group over twelve weeks. The 261 continuous line represents the $50^{\text {th }}$ percentile, whereas the straight (linear) line is a linear 262 regression. MCD, moderately-low-carbohydrate diet; LCD, low-carbohydrate diet; VLCKD, 263 very-low-carbohydrate ketogenic diet

264 Over 12 weeks carbohydrate intake by group was less than allocation for both MCD (22.5\%, SD $265=4.5 \%)$ and $\operatorname{LCD}(14.1 \%, \mathrm{SD}=3.2 \%)$ and higher than allocation for $\operatorname{VLCKD}(7.9 \%, \mathrm{SD}=$ $2664.9 \%$ ). A linear trend was observed for reduction in carbohydrate intake as a proportion of TE for 267 MCD relative to week (Beta $=-0.137, p=0.24)$. Conversely increased intake by week was 268 observed for LCD (Beta $=0.096, p=0.24)$, and VLCKD $(\operatorname{Beta}=0.174, p=0.15)$ but these 269 trends were not significant within groups, or between group allocations $(p=0.108)$. Figure 5 270 shows the reported energy per participant, derived from carbohydrate per group, by week. 


\section{1 [Figure 5.]}

272 Figure 5. Reported carbohydrate intake as a percentage of TE. The continuous line represents the

$27350^{\text {th }}$ percentile. MCD, moderately-low-carbohydrate diet; LCD, low-carbohydrate diet; VLCKD,

274 very-low-carbohydrate ketogenic diet

275 Protein intake did not differ between the groups at baseline $(p=0.299)$. There was no

276 significant variation between groups for average protein intake per day over the course of the

277 study. Fat intake varied by group but was consistent with their total energy intake, and protein

278 and carbohydrate allocations.

\section{Discussion}

\section{Principal findings}

281 Overall, the results demonstrated that reduced carbohydrate diets have a positive effect on select

282 markers of health. Despite a high number of participants who did not present for follow-up

283 testing, in those included for analysis, low-carbohydrate diets were easily adhered to over a 12 -

284 week period. While there was little difference in the consistency of adherence between the

285 differing dietary interventions for calorie and macronutrient allocations overall, carbohydrate

286 intake was more easily maintained in the MCD and LCD groups, as demonstrated by mean

287 intakes lower than allocation, whereas mean intake of carbohydrate as a percentage of TE was

288 higher than allocation in the VLCKD group. There was a marginal increase in energy intake

289 from baseline, but this declined over the course of the study in all groups. Of interest was the

290 relatively low-calorie intake recorded at baseline which might indicate a cohort focussed on

291 weight loss or under-reporting of actual food intake. 
292 Almost all participants began the study with anthropometric and blood measurements within the

293 normal range. We would, therefore, not expect large changes for markers of health in a generally

294 'healthy' cohort. This was also a eucaloric intervention, designed to match habitual energy intake

295 and was not designed as a 'weight loss' trial. Despite this, there were significant and clinically

296 meaningful, albeit relatively small, improvements in weight, waist-height ratio, HDL-c and TG.

297 Of the changes in outcome measures that reached the threshold for significance, seven of nine

298 were improved from baseline favourably (HDL, TG, insulin, weight, waist, hip, and BMI) while

299 only Total-c and LDL-c increased by a small magnitude. Of particular interest, was the

300 improvement in waist-height ratio, as this is a strong predictor of all-cause mortality. (Ashwell et

301 al. 2014) We would also consider the significant improvements in HDL-c and TG to be clinically

302 meaningful measures of interest when compared to relatively minor changes in Total-c or LDL-

303 c. Of all the commonly measured biomarkers of cardiovascular risk, TG concentrations are most

304 convincingly linked to incident cardiovascular disease. (Harcombe et al. 2015; Liu et al. 2013;

305 Ravnskov et al. 2016) Reductions in relative risk are seen at $\mathrm{TG}<1.02 \mathrm{mmol} / \mathrm{L}$, with every 1

$306 \mathrm{mmol} / \mathrm{L}$ increase associated with $\mathrm{a}>12 \%$ increase in risk, for both cardiovascular disease

307 mortality and all-cause mortality. (Liu et al. 2013) Interestingly, in the current study, while mean

308 TG levels were reduced in all groups at 12-weeks, only the VLCKD group showed an

309 improvement in TG levels, with a reduction of $0.04 \mathrm{mmol} / \mathrm{L}$ at the upper limit of the $95 \%$

310 confidence intervals, compared to an increase of $0.16 \mathrm{mmol} / \mathrm{Land} 0.09 \mathrm{mmol} / \mathrm{L}$ for the $\mathrm{MCD}$ and

311 LCD groups, respectively. This suggests that the higher the baseline TG, the greater the benefit

312 of carbohydrate restriction. Our weighted regression re-analysis also showed that baseline TG

313 affected the change in BMI relative to treatment group, suggesting the hypothesis that baseline 
314 lipids may predict outcomes from diets differing in carbohydrate allocation. This hypothesis will

315 be investigated and reported in a separate paper.

316 There is debate around the respective roles that Total-c, LDL-c, HDL-c, TG, and their

317 interactions play with respect to mortality and morbidity outcomes. This warrants further

318 investigation, especially in the context of reduced carbohydrate diets.

319 An additional sensitivity analysis was subsequently carried out which modelled the probability of

320 completing the study, given baseline values of age, gender, weight, TG and glucose

321 concentration using a logistic regression model. These values were then used in a re-analysis of

322 the change in BMI at the end of the study with observations re-weighted by stabilised-inverse

323 probability of treatment from the logistic model. This model showed a larger decrease in mean

324 BMI, comparing the VLCKD to the MCD group (mean change from baseline: $-0.59 \mathrm{~kg} / \mathrm{m}^{2} ; 95 \%$

325 CI: 0.21 to -1.39 ). This difference from the unweighted analysis is likely to be due to different

326 effects of the diets by baseline triglyceride concentration. These changes will be explored further

327 in a future analysis.

328 Several CRP readings were above the reference range of $<5 \mathrm{mg} / \mathrm{L}$. The highest reading of 46.9

$329 \mathrm{mg} / \mathrm{L}$, recorded in the MCD group, was found, on subsequent investigation to be due to an

330 unreported flu-like viral infection. At the conclusion of the study, all results for CRP were $<5$

$331 \mathrm{mg} / \mathrm{L}$. This suggests a positive effect on systemic inflammation from low-carbohydrate diets

332 overall, but high baseline results may have been due to undisclosed illness or another stressor.

333 Strengths and weaknesses of the study

334 This study is one of the first to compare eucaloric diets differing in the magnitude of

335 carbohydrate restriction for anthropometric and cardiometabolic outcomes in healthy people. It 
336 was a randomised trial, including food tracking with real-time researcher monitoring and

337 feedback, along with advice and information provided to participants from a competent team

338 with extensive experience in the prescription of LCDs and VLCKDs. As such, we believe it

339 provides a valuable addition to the literature to help inform clinical practice.

340 Our study was limited by small sample size and by the failure of $49 \%$ of participants to either

341 complete the intervention or present for follow-up testing. This was expected, as high dropout

342 rates are common in dietary studies. For example, a systematic review of low-carbohydrate diets

343 vs low-fat, calorie restricted diet interventions showed an overall attrition rate of $36 \%$, with a

344 higher rate of attrition in low-fat, high-carbohydrate interventions. (Hession et al. 2009) Few

345 participants reported dropping out due to challenges with the diets and most dropouts were

346 instead due to failure to present for testing rather than failure to adhere to the diet, and these

347 numbers were almost identical between the intervention groups. Participants who failed to

348 present were asked to provide reasons for (not) doing so. Two participants responded, stating a

349 clash with work and inability to attend due to parental responsibilities. It is therefore unclear

350 whether there were other factors, outside of scheduling or other logistical challenges, that

351 affected participants completing the study.

352 The final numbers included in our analysis due to attrition, therefore lacked statistical power.

353 With larger numbers, greater statistical significance may be detected. This will be of value to

354 elucidate the impact of differing magnitudes of carbohydrate restriction on important markers of

355 cardiometabolic health in which there was a between group difference in change from baseline,

356 for example, TG and HDL-c. The small sample size also highlights a potential problem of

357 applying parametric tests i.e., whether or not the data collected fit the probability distributions

358 associated with them. An alternative that does not rely on such assumptions is a randomisation 
359 test. Results from these tests in our study were very similar to those obtained from $t$-tests, for 360 example, the $p$-value for the between group differences in change from baseline Total-c was $p=$ 3610.658 which was very similar to the results of the ANOVA, $p=0.686$.

362 The study also did not include a group with a higher carbohydrate allocation consistent with 363 existing dietary guidelines of $45-65 \%$ of energy derived from carbohydrate, (Council. 2006) (i.e., 364 a true control group) and therefore, we cannot discount that higher-carbohydrate, lower-fat diets 365 with an emphasis on high quality food intake, a reduced preponderance of refined, energy-dense 366 foods, nutrition counselling as available in this study, and the accountability of being involved in 367 a study, could lead to similar beneficial results. In the recent DIETFITS study a higher- and 368 lower-carbohydrate intervention, with nutritional counselling and an emphasis on 'quality' 369 nutrition resulted in similar results for weight-loss over twelve months. (Gardner et al. 2018)

370 However, in this study there was a non-significant trend towards greater weight loss, and

371 statistically significant improvements in HDL-c and TG in the lower-carbohydrate group. In the

372 present study, these were improved in a dose-dependent fashion per carbohydrate restriction.

373 There is already a large body of evidence comparing low- to high-carbohydrate diets, and this 374 study helps to instead differentiate between differing lower-carbohydrate diets and their benefits.

375 Meanings and implications of the study

376 The consistency of the improvements in important predictors of mortality suggest a beneficial 377 effect of lower carbohydrate interventions overall, and similarly, towards greater improvement 378 on the most meaningful markers of health, concomitant to the magnitude of carbohydrate 379 restriction. This is of particular interest because the dietary interventions were not hypocaloric 380 and were designed to match habitual energy intake. Yet, despite matching the calorie intake at 381 baseline to the dietary prescription, meaningful anthropometric and blood measures of 
382 cardiometabolic health, were improved and trended towards greater (non-significant)

383 improvements with greater carbohydrate restriction. However, the adherence to the carbohydrate

384 allocation was more likely to be achieved in those on more moderate carbohydrate-restricted

385 diets.

386 Unanswered questions and directions for future research

387 This study shows positive effects overall from reduced carbohydrate diets on select markers of

388 health and further suggests a potential benefit from a greater magnitude of carbohydrate

389 restriction, despite this greater carbohydrate restriction being more difficult to achieve.

390 Additional research with larger sample sizes is warranted to investigate this further. Due to the

391 large numbers that failed to present for follow-up testing, further investigation is warranted to

392 ascertain factors associated with adherence to the diet.

393 Conclusion

394 Low-carbohydrate diets are beneficial for the improvement of anthropometric and blood markers

395 of cardiometabolic health in healthy adults and are easily adhered to over 12-weeks. However,

396 the greatest restriction of carbohydrate to $5 \%$ of TE may not be realistically achievable for this

397 population. Our results demonstrate that non-hypocaloric, low-carbohydrate diets, matched to

398 habitual calorie intake, result in significant improvements in predictors of long-term health

399 including weight, waist and hip girth, waist-to-height ratio, TG and HDL-c, which increase in

400 magnitude with a greater degree of carbohydrate restriction. However, between-group

401 differences typically did not reach thresholds for statistical significance, and further research

402 with larger samples is required to investigate further, the effects of different degrees of

403 carbohydrate restrictions on outcomes in healthy populations. 
404 Acknowledgements

405 We are grateful to the participants in this study. We acknowledge the support of our colleagues

406 at the Human Potential Centre, AUT University, especially Dee Holdsworth-Perks; and at the

407 Holistic Performance Institute. Specifically, we would like to acknowledge the assistance of

408 Amberleigh Jack, Bella Marinkovich, Emily White, and Lulu Caitcheon who assisted with data

409 collection; phlebotomists, Brenda Costa-Scorse and Claudia Barclay; Kirsten Beynon for lab

410 assistance during data collection and analysis, Dave Shaw for his co-operation during data-

411 collection, and Eric Helms and Nigel Harris for advice about the study design and methods.

\section{References}

412

413

414

415

416

417

418

419

420

421

422

423

424

425

426

427

428

429

430

431

432

433

434

435

436

437
Ashwell M, Mayhew L, Richardson J, and Rickayzen B. 2014. Waist-to-Height Ratio Is More Predictive of Years of Life Lost than Body Mass Index. PLoS One 9:e103483. 10.1371/journal.pone.0103483

Babio N, Martínez-González MA, Estruch R, Wärnberg J, Recondo J, Ortega-Calvo M, Serra-Majem L, Corella D, Fitó M, Ros E, Becerra-Tomás N, Basora J, and Salas-Salvadó J. 2015. Associations between serum uric acid concentrations and metabolic syndrome and its components in the PREDIMED study. Nutrition, Metabolism and Cardiovascular Diseases 25:173-180. 10.1016/j.numecd.2014.10.006

Ballestri S, Zona S, Targher G, Romagnoli D, Baldelli E, Nascimbeni F, Roverato A, Guaraldi G, and Lonardo A. 2016. Nonalcoholic fatty liver disease is associated with an almost twofold increased risk of incident type 2 diabetes and metabolic syndrome. Evidence from a systematic review and meta-analysis. J Gastroenterol Hepatol 31:936-944. 10.1111/jgh.13264

Bueno NB, de Melo ISV, de Oliveira SL, and da Rocha Ataide T. 2013. Very-low-carbohydrate ketogenic diet v. low-fat diet for long-term weight loss: a meta-analysis of randomised controlled trials. $\mathrm{Br}$ J Nutr 110:1178-1187. doi:10.1017/S0007114513000548

Campbell B, Kreider RB, Ziegenfuss T, La Bounty P, Roberts M, Burke D, Landis J, Lopez H, and Antonio J. 2007. International Society of Sports Nutrition position stand: protein and exercise. Journal of the International Society of Sports Nutrition 4:8-8. 10.1186/1550-2783-4-8

Castro K, Faccioli LS, Baronio D, Gottfried C, Perry IS, and dos Santos Riesgo R. 2015. Effect of a ketogenic diet on autism spectrum disorder: A systematic review. Res Autism Spectr Disord 20:31-38. https://doi.org/10.1016/j.rasd.2015.08.005

Council. NHaMR. 2006. Nutrient Reference Values for Australia and New Zealand. In: Department of Health and Ageing NZMoH, editor. Canberra: National Health and Medical Research Council.

Gardner CD, Trepanowski JF, Del Gobbo LC, Hauser ME, Rigdon J, lonnidis JPA, Desai M, and King AC. 2018. Effect of low-fat vs low-carbohydrate diet on 12-month weight loss in overweight adults and the association with genotype pattern or insulin secretion: The dietfits randomized clinical trial. JAMA 319:667-679. 10.1001/jama.2018.0245 
438

439

440

441

442

443

444

445

446

447

448

449

450

451

452

453

454

455

456

457

458

459

460

461

462

463

464

465

466

467

468

469

470

471

472

473

474

475

476

477

478

479

480

481

482

483

484

Gibson A, Seimon R, Lee C, Ayre J, Franklin J, Markovic T, Caterson I, and Sainsbury A. 2015. Do ketogenic diets really suppress appetite? A systematic review and meta-analysis. Obes Rev 16:64-76.

Guerci B, Benichou M, Floriot M, Bohme P, Fougnot S, Franck P, and Drouin P. 2003. Accuracy of an electrochemical sensor for measuring capillary blood ketones by fingerstick samples during metabolic deterioration after continuous subcutaneous insulin infusion interruption in type 1 diabetic patients. Diabetes Care 26:1137-1141. 10.2337/diacare.26.4.1137

Harcombe Z, Baker JS, Cooper SM, Davies B, Sculthorpe N, DiNicolantonio JJ, and Grace F. 2015. Evidence from randomised controlled trials did not support the introduction of dietary fat guidelines in 1977 and 1983: a systematic review and meta-analysis. Open Heart 2.

Harvey CJdC, Schofield GM, Williden M, and McQuillan JA. 2018. The Effect of Medium Chain Triglycerides on Time to Nutritional Ketosis and Symptoms of Keto-Induction in Healthy Adults: A Randomised Controlled Clinical Trial. J Nutr Metab 2018:9. 10.1155/2018/2630565

Henderson CB, Filloux FM, Alder SC, Lyon JL, and Caplin DA. 2006. Efficacy of the ketogenic diet as a treatment option for epilepsy: Meta-analysis. J Child Neurol 21:193-198. 10.2310/7010.2006.00044

Hernández Alcantara G, Jiménez Cruz A, and Bacardí Gascón M. 2015. Effect of low carbohydrate diets on weight loss and glycosilated hemoglobin in people with type 2 diabetes: Systematic review. Nutricion hospitalaria. p 1960-1966.

Hession M, Rolland C, Kulkarni U, Wise A, and Broom J. 2009. Systematic review of randomized controlled trials of low-carbohydrate vs. low-fat/low-calorie diets in the management of obesity and its comorbidities. Obes Rev 10:36-50. 10.1111/j.1467-789X.2008.00518.x

Hu T, Mills KT, Yao L, Demanelis K, Eloustaz M, Yancy WS, Kelly TN, He J, and Bazzano LA. 2012. Effects of Low-Carbohydrate Diets Versus Low-Fat Diets on Metabolic Risk Factors: A Meta-Analysis of Randomized Controlled Clinical Trials. Am J Epidemiol 176:S44-S54. 10.1093/aje/kws264

Huntriss R, Campbell M, and Bedwell C. 2017. The interpretation and effect of a low-carbohydrate diet in the management of type 2 diabetes: a systematic review and meta-analysis of randomised controlled trials. Eur J Clin Nutr. 10.1038/s41430-017-0019-4

Huttenlocher P, Wilbourn A, and Signore J. 1971. Medium-chain triglycerides as a therapy for intractable childhood epilepsy. Neurology 21:1097-1097.

Huttenlocher PR. 1976. Ketonemia and seizures: Metabolic and anticonvulsant effects of two ketogenic diets in childhood epilepsy. Pediatr Res 10:536-540.

Johnston CS, Tjonn SL, Swan PD, White A, Hutchins H, and Sears B. 2006. Ketogenic low-carbohydrate diets have no metabolic advantage over nonketogenic low-carbohydrate diets. Am J Clin Nutr 83:1055-1061.

Johnstone AM, Horgan GW, Murison SD, Bremner DM, and Lobley GE. 2008. Effects of a high-protein ketogenic diet on hunger, appetite, and weight loss in obese men feeding ad libitum. Am J Clin Nutr 87:44-55.

Keene DL. 2006. A systematic review of the use of the ketogenic diet in childhood epilepsy. Pediatr Neurol 35:1-5. http://dx.doi.org/10.1016/j.pediatrneurol.2006.01.005

Kulak D, and Polotsky AJ. 2013. Should the ketogenic diet be considered for enhancing fertility? Maturitas 74:10-13. http://dx.doi.org/10.1016/j.maturitas.2012.10.003

Last AR, and Wilson SA. 2006. Low-carbohydrate diets. Am Fam Physician 73:1951-1958.

Lefevre F, and Aronson N. 2000. Ketogenic diet for the treatment of refractory epilepsy in children: A systematic review of efficacy. Pediatrics 105:e46.

Levy RG, Cooper PN, Giri P, and Pulman J. 2012. Ketogenic diet and other dietary treatments for epilepsy. The Cochrane Library. 
485

486

487

488

489

490

491

492

493

494

495

496

497

498

499

500

501

502

503

504

505

506

507

508

509

510

511

512

513

514

515

516

517

518

519

520

521

522

523

524

525

526

527

528

529

530

531

Liu J, Zeng F-F, Liu Z-M, Zhang C-X, Ling W-h, and Chen Y-M. 2013. Effects of blood triglycerides on cardiovascular and all-cause mortality: a systematic review and meta-analysis of 61 prospective studies. Lipids Health Dis 12:159. 10.1186/1476-511X-12-159

Livingston S, Pauli LL, and Pruce I. 1977. KETOGENIC DIET IN TREATMENT OF CHILDHOOD EPILEPSY. Developmental Medicine and Child Neurology 19:833-834.

Livingstone S. 1972. Comprehensive Management of Epilepsy in Infancy, Childhood and Adolescence. Archives of Disease in Childhood 47:842-842.

Maalouf M, Rho JM, and Mattson MP. 2009. The neuroprotective properties of calorie restriction, the ketogenic diet, and ketone bodies. Brain Res Rev 59:293-315. 10.1016/j.brainresrev.2008.09.002

McClain AD, Otten JJ, Hekler EB, and Gardner CD. 2013. Adherence to a low-fat vs. low-carbohydrate diet differs by insulin resistance status. Diabetes Obes Metab 15:87-90. 10.1111/j.14631326.2012.01668.x

McClernon FJ, Yancy WS, Jr., Eberstein JA, Atkins RC, and Westman EC. 2007. The effects of a lowcarbohydrate ketogenic diet and a low-fat diet on mood, hunger, and other self-reported symptoms. Obesity (Silver Spring) 15:182-187. 10.1038/oby.2007.516

Naude CE, Schoonees A, Senekal M, Young T, Garner P, and Volmink J. 2014. Low Carbohydrate versus Isoenergetic Balanced Diets for Reducing Weight and Cardiovascular Risk: A Systematic Review and Meta-Analysis. PLoS One 9:e100652. 10.1371/journal.pone.0100652

Neal EG, Chaffe H, Schwartz RH, Lawson MS, Edwards N, Fitzsimmons G, Whitney A, and Cross JH. 2008. The ketogenic diet for the treatment of childhood epilepsy: a randomised controlled trial. Lancet Neurol 7:500-506. http://dx.doi.org/10.1016/S1474-4422(08)70092-9

Paoli A, Bosco G, Camporesi E, and Mangar D. 2015. Ketosis, ketogenic diet and food intake control: a complex relationship. Frontiers in Psychology 6. 10.3389/fpsyg.2015.00027

Paoli A, Rubini A, Volek J, and Grimaldi K. 2013. Beyond weight loss: a review of the therapeutic uses of very-low-carbohydrate (ketogenic) diets. Eur J Clin Nutr 67:789-796.

Ravnskov U, Diamond DM, Hama R, Hamazaki T, Hammarskjold B, Hynes N, Kendrick M, Langsjoen PH, Malhotra A, Mascitelli L, McCully KS, Ogushi Y, Okuyama H, Rosch PJ, Schersten T, Sultan S, and Sundberg R. 2016. Lack of an association or an inverse association between low-densitylipoprotein cholesterol and mortality in the elderly: a systematic review. BMJ Open 6:e010401. 10.1136/bmjopen-2015-010401

Snorgaard O, Poulsen GM, Andersen HK, and Astrup A. 2017. Systematic review and meta-analysis of dietary carbohydrate restriction in patients with type 2 diabetes. BMJ Open Diabetes Res Care 5.

Sumithran P, and Proietto J. 2008. Ketogenic diets for weight loss: A review of their principles, safety and efficacy. Obes Res Clin Pract 2:1-13. http://dx.doi.org/10.1016/j.orcp.2007.11.003

van Wyk HJ, Davis RE, and Davies JS. 2016. A critical review of low-carbohydrate diets in people with Type 2 diabetes. Diabet Med 33:148-157. 10.1111/dme.12964

Varshneya K, Carico C, Ortega A, and Patil CG. 2015. The efficacy of ketogenic diet and associated hypoglycemia as an adjuvant therapy for high-grade gliomas: A review of the literature. Cureus 7:e251. 10.7759/cureus.251

Westman EC, Feinman RD, Mavropoulos JC, Vernon MC, Volek JS, Wortman JA, Yancy WS, and Phinney SD. 2007. Low-carbohydrate nutrition and metabolism. Am J Clin Nutr 86:276-284.

Wheeler ML, Dunbar SA, Jaacks LM, Karmally W, Mayer-Davis EJ, Wylie-Rosett J, and Yancy WS. 2012. Macronutrients, Food Groups, and Eating Patterns in the Management of Diabetes A systematic review of the literature, 2010. Diabetes Care 35:434-445.

Wood RJ, and Fernandez ML. 2009. Carbohydrate-restricted versus low-glycemic-index diets for the treatment of insulin resistance and metabolic syndrome. Nutr Rev 67:179-183. 10.1111/j.17534887.2009.00186. $x$ 
Appendix 1. Assay performance.

\begin{tabular}{|c|c|c|c|}
\hline Analyte & $\begin{array}{l}\text { Lower limit of } \\
\text { measurement* }\end{array}$ & Measuring range & Test principle \\
\hline Total cholesterol & $0.1 \mathrm{mmol} / \mathrm{L}$ & $0.1-20.7 \mathrm{mmol} / \mathrm{L}$ & Enzymatic colorimetric test \\
\hline LDL-c & $0.078 \mathrm{mmol} / \mathrm{L}$ & $\begin{array}{l}0.078-14.2 \\
\mathrm{mmol} / \mathrm{L}\end{array}$ & $\begin{array}{l}\text { Homogeneous enzymatic } \\
\text { colorimetric assay }\end{array}$ \\
\hline HDL-c & $0.08 \mathrm{mmol} / \mathrm{L}$ & $0.08-3.10 \mathrm{mmol} / \mathrm{L}$ & $\begin{array}{l}\text { Homogeneous enzymatic } \\
\text { colorimetric assay }\end{array}$ \\
\hline TG & $0.05 \mathrm{mmol} / \mathrm{L}$ & $0.05-11.3 \mathrm{mmol} / \mathrm{L}$ & Enzymatic colorimetric test \\
\hline CRP & $2.9 \mathrm{nmol} / \mathrm{L}$ & $2.9-3333 \mathrm{nmol} / \mathrm{L}$ & $\begin{array}{l}\text { Particle-enhanced } \\
\text { immunoturbidimetric assay }\end{array}$ \\
\hline GGT & $3 \mathrm{U} / \mathrm{L}$ & $3-1,200 \mathrm{U} / \mathrm{L}$ & Enzymatic colorimetric test \\
\hline ALT & $5 \mathrm{U} / \mathrm{L}$ & $5-700 \mathrm{U} / \mathrm{L}$ & Enzymatic colorimetric test \\
\hline AST & $5 \mathrm{U} / \mathrm{L}$ & $5-700 \mathrm{U} / \mathrm{L}$ & Enzymatic colorimetric test \\
\hline ALP & $3 \mathrm{U} / \mathrm{L}$ & $3-1200 \mathrm{U} / \mathrm{L}$ & Enzymatic colorimetric test \\
\hline Glucose & $0.11 \mathrm{mmol} / \mathrm{L}$ & $0.11-41.6 \mathrm{mmol} / \mathrm{L}$ & Enzymatic colorimetric test \\
\hline Uric acid & $11.9 \mu \mathrm{mol} / \mathrm{L}$ & $11.9-1487 \mu \mathrm{mol} / \mathrm{L}$ & Enzymatic colorimetric test \\
\hline Insulin & $1.39 \mathrm{pmol} / \mathrm{L}$ & $1.39-6945 \mathrm{pmol} / \mathrm{L}$ & Electrochemoluminescence \\
\hline C-peptide & $0.003 \mathrm{mmol} / \mathrm{L}$ & $0.003-13.3 \mathrm{nmol} / \mathrm{L}$ & Electrochemoluminescence \\
\hline
\end{tabular}

* Functional sensitivity. It represents the lowest measurable analyte level that can be distinguished from zero. It is calculated as the value lying two or three standard deviations above that of the lowest standard. Method comparisons, limitations and specific performance data can be found on www.e-labdoc.roche.com 


\section{Figure 1}

Flow of participants with dietary allocations during the study period.

\begin{tabular}{|l|l|l|}
\hline $\begin{array}{l}\text { Lead-in week } \\
\text { - Baseline testing } \\
\text { energy intake }\end{array}$ & $\begin{array}{l}\text { Intervention } \\
\text { Weeks 1-3 }\end{array}$ \\
$\begin{array}{l}\text { Energy intake } \\
\text { advised to } \\
\text { continue at } \\
\text { baseline level } \\
\text { Total } \\
\text { macronutrient } \\
\text { intake } \\
\text { prescribed. }\end{array}$ & $\begin{array}{l}\text { Intervention } \\
\text { Weeks 4-12 }\end{array}$ \\
$\begin{array}{l}\text { Thalories ad- } \\
\text { libitum } \\
\text { Carbohydrate } \\
\text { allocation as a } \\
\text { proportion of } \\
\text { energy } \\
\text { prescribed. }\end{array}$ \\
\hline
\end{tabular}


Figure 2

Participants included for participation, randomisation, allocation, and lost to follow up.

Assessed for eligibility $(n=283)$

Total Excluded ( $\mathrm{N}=206$ )

Not meeting inclusion criteria $(n=143)$

Chose not to participate $(n=15)$

Could not attend baseline testing $(n=13)$

Failed to respond $(n=35)$

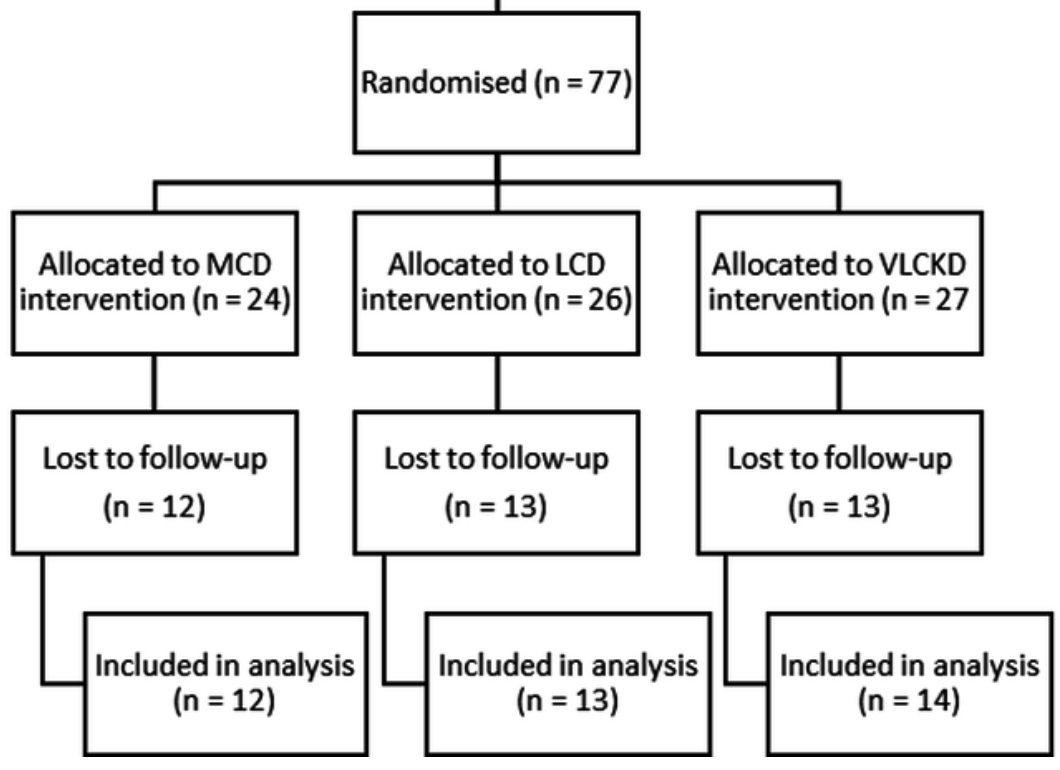


Figure 3

Percentage change from baseline in cardiometabolic and athropometric outcome measures

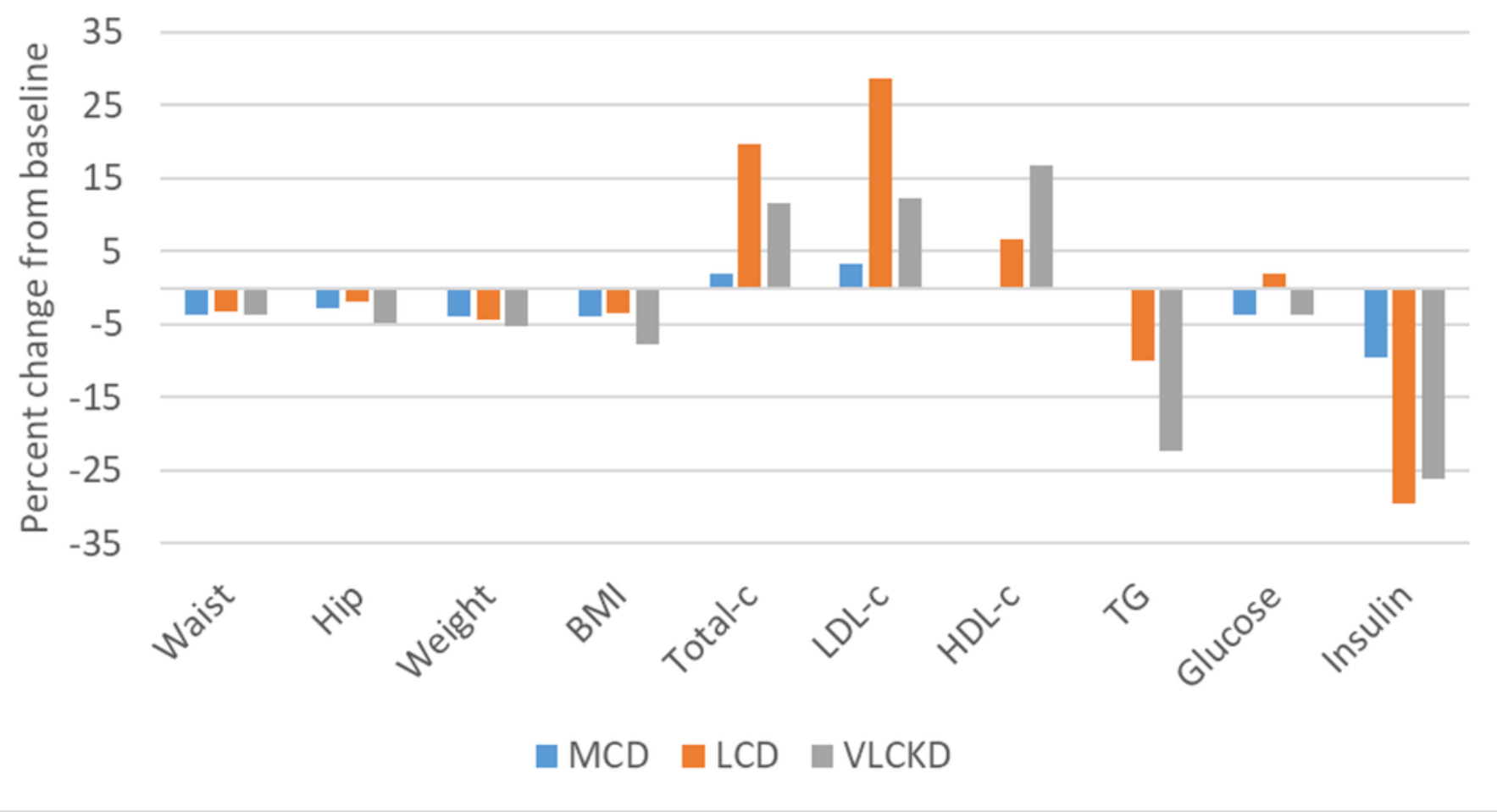


Figure 4 (on next page)

Mean daily energy intake by week per participant.

The blue line indicates the linear trend. Black line indicates the 50th percentile. 
PeerJ

Manuscript to be reviewed

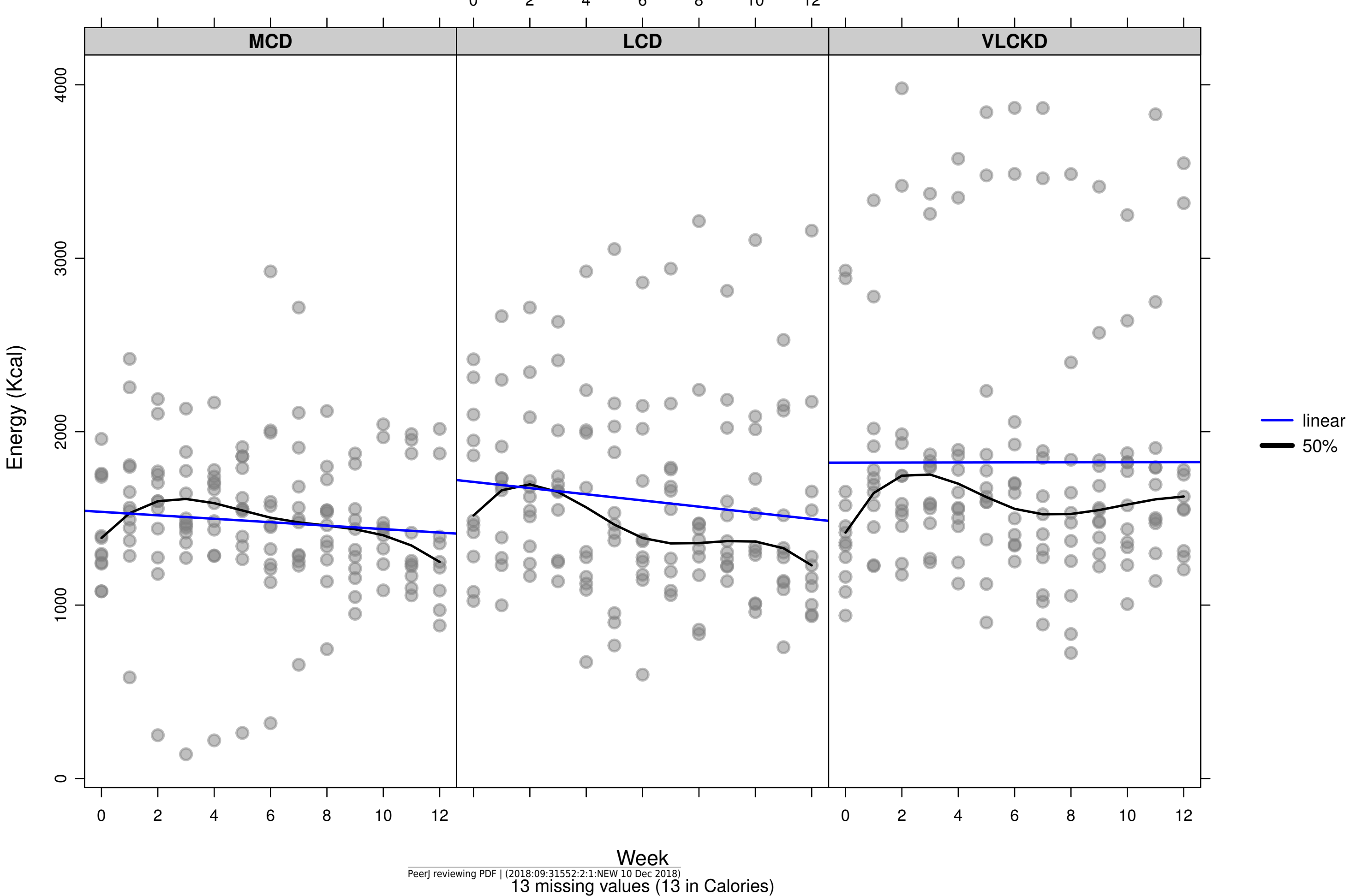


Figure $\mathbf{5}$ (on next page)

Mean percent of total energy derived from carbohydrate by participant, per week.

The black line indicates the 50th percentile. 


\section{PeerJ}

$\underset{10}{\text { Manuscript to be reviewed }}$

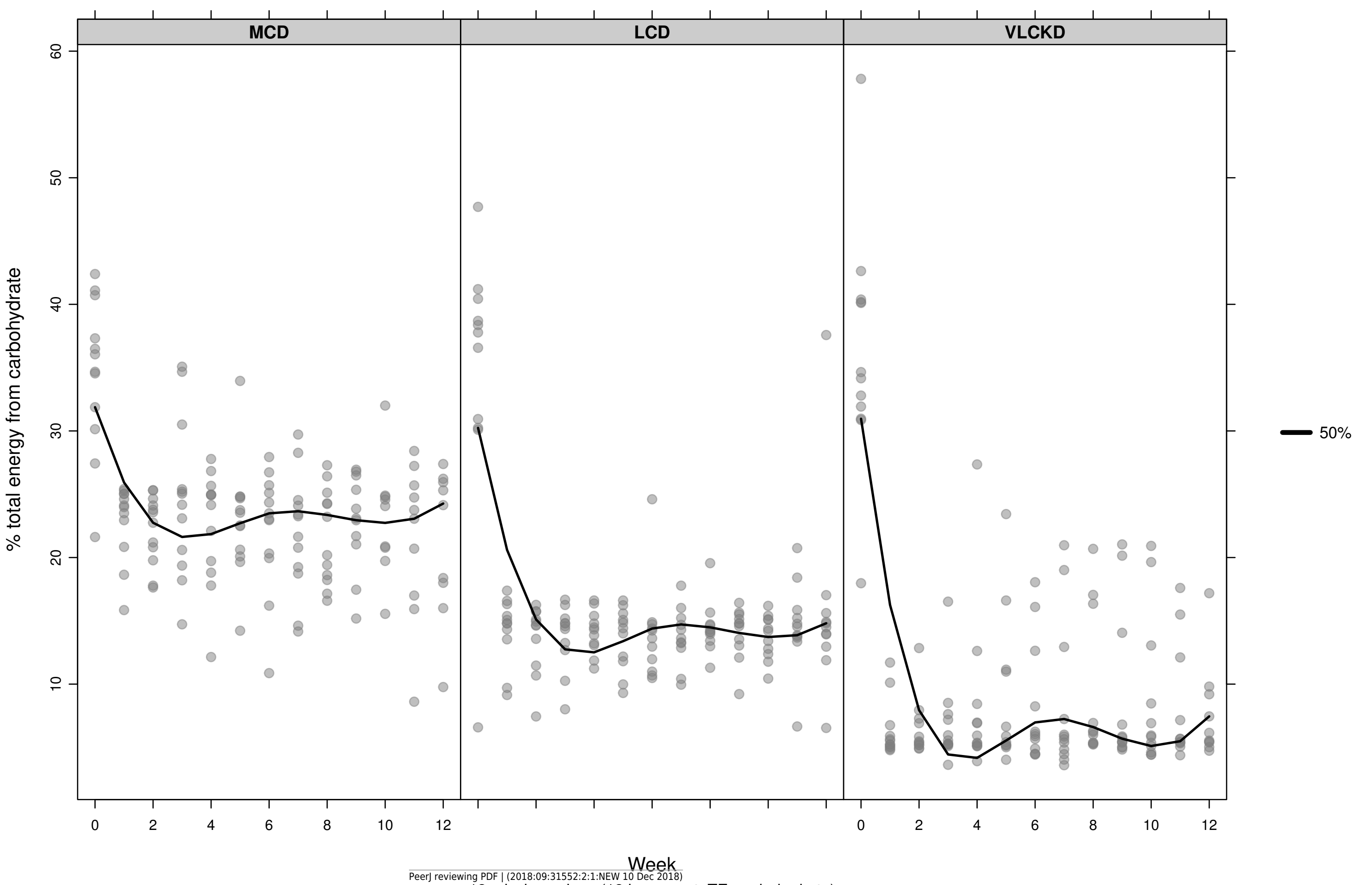

13 missing values (13 in percent_TE_carbohydrate) 


\section{Table $\mathbf{1}$ (on next page)}

Baseline characteristics of study participants. 
1 Table 1. Baseline characteristics of study participants

\begin{tabular}{|c|c|c|c|c|c|c|}
\hline & & reatment gr & & & & \\
\hline & MCD & LCD & VLCKD & Total & Test & $p$-value \\
\hline & 12 & 13 & 14 & 39 & & \\
\hline $\begin{array}{l}\text { Age } \\
\text { mean (SD) }\end{array}$ & $39.1(6.6)$ & $38.9(8.3)$ & $38.7(7.1)$ & $38.9(7.1)$ & ANOVA & 0.992 \\
\hline Gender (\%) & & & & & Fisher's & 0.198 \\
\hline Female & $10(83.3)$ & $6(46.2)$ & $9(64.3)$ & $25(64.1)$ & & \\
\hline Male & $2(16.67)$ & $7(53.85)$ & $5(35.71)$ & $14(35.9)$ & & \\
\hline Ethnicity (\%) & & & & & Fisher's & 0.733 \\
\hline Asian & $1(8.3)$ & $0(0.0)$ & $1(7.1)$ & $2(5.1)$ & & \\
\hline European & $8(66.7)$ & $11(84.6)$ & $10(71.4)$ & $29(74.4)$ & & \\
\hline Maori & $2(16.7)$ & $1(7.7)$ & $3(21.4)$ & $6(15.4)$ & & \\
\hline Other ethnicity & $1(8.3)$ & $0(0.0)$ & $0(0.0)$ & $1(2.6)$ & & \\
\hline Pacific peoples & $0(0.0)$ & $1(7.7)$ & $0(0.0)$ & $1(2.6)$ & & \\
\hline $\begin{array}{l}\text { Total energy } \\
\text { (Kcal) } \\
\text { mean (SD) }\end{array}$ & 1435 (293) & 1567 (666) & $1805(857)$ & $1603(649)$ & ANOVA & 0.378 \\
\hline $\begin{array}{l}\text { Weight }(\mathrm{kg}) \\
\text { mean }(\mathrm{SD})\end{array}$ & $76.3(14.9)$ & $90.4(20.0)$ & $76.8(11.2)$ & $81.2(16.6)$ & ANOVA & 0.046 \\
\hline $\begin{array}{l}\text { Height (m) } \\
\text { mean (SD) }\end{array}$ & $1.70(0.10)$ & $1.76(0.08)$ & $1.74(0.09)$ & $1.73(0.09)$ & ANOVA & 0.245 \\
\hline $\begin{array}{l}\text { BMI }\left(\mathrm{kg} / \mathrm{m}^{2}\right) \\
\text { mean }(\mathrm{SD})\end{array}$ & $26.4(3.23)$ & $29.1(4.92)$ & $25.5(2.77)$ & $27.0(3.96)$ & ANOVA & 0.050 \\
\hline $\begin{array}{l}\text { Glucose } \\
(\mathrm{mmol} / \mathrm{L}) \\
\text { mean }(\mathrm{SD})\end{array}$ & $5.54(0.43)$ & $5.38(0.47)$ & $5.44(0.44)$ & $5.45(0.44)$ & ANOVA & 0.673 \\
\hline $\begin{array}{l}\text { Total cholesterol } \\
(\mathrm{mmol} / \mathrm{L}) \\
\text { mean }(\mathrm{SD})\end{array}$ & $5.20(1.3)$ & $4.57(0.61)$ & $6.10(1.37)$ & $5.31(1.29)$ & ANOVA & 0.005 \\
\hline $\begin{array}{l}\text { Triglyceride } \\
(\mathrm{mmol} / \mathrm{L}) \\
\text { mean }(\mathrm{SD})\end{array}$ & $0.79(0.2)$ & $0.99(0.36)$ & $0.92(0.22)$ & $0.90(0.27)$ & ANOVA & 0.184 \\
\hline $\begin{array}{l}\text { Insulin }(\mathrm{pmol} / \mathrm{L}) \\
\text { mean }(\mathrm{SD})\end{array}$ & $63.1(37.3)$ & $81.1(39.4)$ & $41.6(17.6)$ & $61.4(35.8)$ & ANOVA & 0.012 \\
\hline
\end{tabular}

2 SD: standard deviation; BMI: body mass index 
Table 2 (on next page)

Change in outcome measures, overall, and by group. 
1 Table 2. Change in outcome measures 


\begin{tabular}{|c|c|c|c|c|}
\hline \multirow[t]{2}{*}{ Measure } & \multirow{2}{*}{$\begin{array}{l}\text { Overall change } \dagger \\
\text { Mean change } \\
\text { from baseline } \\
{[95 \% \mathrm{CI}]}\end{array}$} & \multicolumn{3}{|c|}{$\begin{array}{c}\text { Treatment group } \\
\text { Mean change from baseline }[95 \% \mathrm{CI}]\end{array}$} \\
\hline & & $\begin{array}{c}\text { Moderate-low } \\
\text { carbohydrate diet }\end{array}$ & $\begin{array}{l}\text { Low carbohydrate } \\
\text { diet }\end{array}$ & $\begin{array}{c}\text { Very low } \\
\text { carbohydrate } \\
\text { ketogenic diet }\end{array}$ \\
\hline \multirow[t]{2}{*}{ Weight (kg) } & \multirow{2}{*}{$\begin{array}{c}-3.70 \\
{[-4.72,-2.68]} \\
p<0.01\end{array}$} & $\begin{array}{c}-2.97 \\
{[-5.03,-0.90]}\end{array}$ & $\begin{array}{c}-3.93 \\
{[-6.17,-1.69]}\end{array}$ & $\begin{array}{c}-4.12 \\
{[5.58,-2.65]}\end{array}$ \\
\hline & & \multicolumn{3}{|c|}{$p=0.63$} \\
\hline \multirow[t]{2}{*}{$\begin{array}{l}\text { Waist circumference } \\
(\mathrm{cm})\end{array}$} & \multirow{2}{*}{$\begin{array}{c}-2.85 \\
{[-3.82,-1.88]} \\
p<0.01\end{array}$} & $\begin{array}{c}-2.95 \\
{[-5.57,-0.33]}\end{array}$ & $\begin{array}{c}-2.80 \\
{[-4.62,-0.98]}\end{array}$ & $\begin{array}{c}-2.81 \\
{[-3.88,-1.75]}\end{array}$ \\
\hline & & \multicolumn{3}{|c|}{$p=0.99$} \\
\hline \multirow[t]{2}{*}{$\begin{array}{l}\text { Hip } \\
(\mathrm{cm})\end{array}$} & \multirow{2}{*}{$\begin{array}{c}-3.43 \mathrm{~cm} \\
{[-4.95,-1.92]} \\
p<0.01\end{array}$} & $\begin{array}{c}-3.56 \\
{[-5.00,-2.12]}\end{array}$ & $\begin{array}{c}-1.19 \\
{[-4.29,1.91]}\end{array}$ & $\begin{array}{c}-5.40 \\
{[-8.34,-2.46]} \\
\end{array}$ \\
\hline & & \multicolumn{3}{|c|}{$p=0.06$} \\
\hline \multirow[t]{2}{*}{ Waist-height ratio } & \multirow{2}{*}{$\begin{array}{c}-0.02 \\
{[-0.02,-0.01]} \\
p<0.001\end{array}$} & $\begin{array}{c}-0.02 \\
{[-0.03,-0.002]}\end{array}$ & $\begin{array}{c}-0.02 \\
{[-0.03,-0.006]}\end{array}$ & $\begin{array}{c}-0.02 \\
{[-0.02,-0.01]}\end{array}$ \\
\hline & & \multicolumn{3}{|c|}{$p=0.98$} \\
\hline \multirow[t]{2}{*}{ Waist-hip ratio } & \multirow{2}{*}{$\begin{array}{c}-0.003 \\
{[-0.016,0.010]} \\
p=0.66\end{array}$} & $\begin{array}{c}-0.004 \\
{[-0.026,0.018]}\end{array}$ & $\begin{array}{c}-0.017 \\
{[-0.046,0.011]}\end{array}$ & $\begin{array}{c}0.011 \\
{[-0.008,0.030]}\end{array}$ \\
\hline & & \multicolumn{3}{|c|}{$p=0.16$} \\
\hline \multirow[t]{2}{*}{ BMI $\left(\mathrm{kg} / \mathrm{m}^{2}\right)$} & \multirow{2}{*}{$\begin{array}{c}-1.223 \\
{[-1.556,-0.889]} \\
\mathrm{p}<0.001\end{array}$} & $\begin{array}{c}-1.031 \\
{[-1.757,-0.306]}\end{array}$ & $\begin{array}{c}-1.22 \\
{[-1.894,-0.546]}\end{array}$ & $\begin{array}{c}-1.39 \\
{[-1.899,-0.881]}\end{array}$ \\
\hline & & \multicolumn{3}{|c|}{$p=0.686$} \\
\hline \multirow[t]{2}{*}{$\begin{array}{ll}\text { Total } & \text { cholesterol } \\
(\mathrm{mmol} / \mathrm{L}) & \end{array}$} & \multirow{2}{*}{$\begin{array}{c}0.58 \\
{[0.11,1.05]} \\
p=0.02\end{array}$} & $\begin{array}{c}0.08 \\
{[-0.57,0.72]} \\
\end{array}$ & $\begin{array}{c}0.94 \\
{[0.08,1.80]}\end{array}$ & $\begin{array}{c}0.68 \\
{[-0.33,1.69]} \\
\end{array}$ \\
\hline & & \multicolumn{3}{|c|}{$p=0.33$} \\
\hline \multirow[t]{2}{*}{ LDL-c (mmol/L) } & \multirow{2}{*}{$\begin{array}{c}0.49 \\
{[0.06,0.92]} \\
p=0.03\end{array}$} & $\begin{array}{c}0.14 \\
{[-0.39,0.67]} \\
\end{array}$ & $\begin{array}{c}0.80 \\
{[-0.02,1.62]}\end{array}$ & $\begin{array}{c}0.50 \\
{[-0.44,1.44]}\end{array}$ \\
\hline & & \multicolumn{3}{|c|}{$p=0.47$} \\
\hline \multirow[t]{2}{*}{ HDL-c $(\mathrm{mmol} / \mathrm{L})$} & \multirow{2}{*}{$\begin{array}{c}0.11 \\
{[0.00,0.23]} \\
p=0.05\end{array}$} & $\begin{array}{c}-0.05 \\
{[-0.33,0.24]}\end{array}$ & $\begin{array}{c}0.13 \\
{[-0.02,0.27]}\end{array}$ & $\begin{array}{c}0.24 \\
{[0.07,0.42]}\end{array}$ \\
\hline & & \multicolumn{3}{|c|}{$p=0.10$} \\
\hline \multirow[t]{2}{*}{$\begin{array}{l}\text { Triglycerides } \\
(\mathrm{mmol} / \mathrm{L})\end{array}$} & \multirow{2}{*}{$\begin{array}{c}-0.12 \\
{[0.20,-0.02]} \\
p=0.02\end{array}$} & $\begin{array}{c}-0.04 \\
{[-0.22,0.15]}\end{array}$ & $\begin{array}{c}-0.09 \\
{[-0.27,0.09]}\end{array}$ & $\begin{array}{c}-0.18 \\
{[-0.32,-0.04]}\end{array}$ \\
\hline & & & $p=0.41$ & \\
\hline TG-HDL ratio & $\begin{array}{c}-0.101 \\
{[-0.173,-0.030]}\end{array}$ & $\begin{array}{c}-0.023 \\
{[-0.123,0.078]}\end{array}$ & $\begin{array}{c}-0.118 \\
{[-0.294,0.058]} \\
\end{array}$ & $\begin{array}{c}-0.154 \\
{[-0.259,-0.048]}\end{array}$ \\
\hline & $p=0.006$ & & $p=0.31$ & \\
\hline Insulin $(\mathrm{pmol} / \mathrm{L})$ & $\begin{array}{c}-13.58 \\
{[-21.61,-5.56]}\end{array}$ & $\begin{array}{c}-6.45 \\
{[-23.38,10.48]}\end{array}$ & $\begin{array}{c}-23.68 \\
{[-42.49,-4.86]}\end{array}$ & $\begin{array}{c}-10.33 \\
{[-17.03,-3.62]}\end{array}$ \\
\hline & $p<0.01$ & & $p=0.19$ & \\
\hline Glucose $(\mathrm{mmol} / \mathrm{L})$ & $\begin{array}{c}-0.11 \\
{[-0.26,0.04]}\end{array}$ & $\begin{array}{c}-0.22 \\
{[-0.55,0.11]}\end{array}$ & $\begin{array}{c}0.08 \\
{[-0.19,0.34]}\end{array}$ & $\begin{array}{c}-0.20 \\
{[-0.45,0.04]}\end{array}$ \\
\hline & $p=0.14$ & & $p=0.20$ & \\
\hline $\begin{array}{l}\text { c-reactive protein } \\
(\mathrm{mg} / \mathrm{L})\end{array}$ & $\begin{array}{c}-2.16 \\
{[-4.55,0.22]}\end{array}$ & $\begin{array}{c}-3.90 \\
{[-11.90,4.10]}\end{array}$ & $\begin{array}{c}-3.04 \\
{[-5.39,-0.68]}\end{array}$ & $\begin{array}{c}0.14 \\
{[-0.50,0.77]}\end{array}$ \\
\hline & $p=0.07$ & & $p=0.34$ & \\
\hline
\end{tabular}

$\dagger$ Mean change from baseline [95\% CI]; $p$-value relates to repeated measures t-test. $\$$ Mean change from baseline [95\% $\mathrm{CI}$; $p$-value relates to Anova comparing change from baseline within treatment group. BMI, body mass index; LDL-c, low-density lipoprotein cholesterol; HDL-c, high-density lipoprotein cholesterol 